\title{
Microphthalmia transcription factor and NKI/ C3 expression in cellular neurothekeoma
}

\author{
Robert N Page ${ }^{1,2}$, Roy King ${ }^{1,2}$, Martin C Mihm Jr ${ }^{3}$ and Paul B Googe ${ }^{1,2,4}$ \\ ${ }^{1}$ Knoxville Dermatopathology Laboratory; ${ }^{2}$ Department of Pathology, University of Tennessee, Knoxville, TN, \\ USA; ${ }^{3}$ Massachusetts General Hospital and Harvard Medical School, Boston, MA, USA and ${ }^{4}$ Department of \\ Pathology, Vanderbilt University, Nashville, TN, USA
}

\begin{abstract}
While the usual or myxoid-type neurothekeoma has been reasonably well established as being a tumor of neural origin, the cellular neurothekeoma remains in disputed histogenesis. We studied a series of 11 cellular neurothekeomas using paraffin immunoperoxidase staining with microphthalmia transcription factor (Mitf), $\mathrm{NKI} / \mathrm{C} 3$, and S-100. The majority of the tumors in our series stained with NKI/C3 (9/11) and Mitf (9/11). All failed to stain with S-100. Furthermore, we divided our series of cellular neurothekeomas according to cytomorphology; tumors demonstrating predominantly spindled morphology, predominantly epithelioid morphology, and mixed spindle and epithelioid morphology. The two tumors that failed to stain with NKI/C3 both demonstrated predominantly spindled morphology. One of the tumors that failed to stain with Mitf showed exclusive spindled morphology, while the other showed mixed morphology (spindle and epithelioid). Two of the tumors, which stained strongly with Mitf, however, showed exclusive epithelioid morphology. This current study furthers the concept that cellular neurothekeoma is a tumor of neuroectodermal origin, and further suggests that it may express some component of melanocytic differentiation.
\end{abstract}

Modern Pathology (2004) 17, 230-234, advance online publication, 19 December 2003; doi:10.1038/modpathol.3800043

Keywords: neurothekeoma; microphthalmia transcription factor; NKIC3; immunohistochemistry

Cellular neurothekeoma is an uncommon benign cutaneous neoplasm of uncertain histogenesis. Cellular neurothekeomas are often composed of spindled and epithelioid cells arranged in nests within the dermis, and sometimes resemble melanocytic neoplasia in routine histological sections. Immunohistochemical stains are helpful in discriminating cellular neurothekeoma from melanocytic neoplasia. Cellular neurothekeoma is typically reactive for NKI/C3, smooth muscle actin and neuron specific enolase and fails to stain with S-100 protein or HMB 45.

We have added anti-microphthalmia transcription factor (Mitf) to the battery of immunohistochemical stains used in our laboratory for studying possible melanocytic neoplasms The protein encoded by the microphthalmia gene is a transcription factor essential for the development and survival of melanocytes. Humans with the heterozygous mutations of Mitf have Waardenberg syndrome type II, a condition characterized by white forelock and

Correspondence: RN Page, Knoxville Dermatopathology Laboratory, 315 Erin Drive, Knoxville, TN 37919, USA.

E-mail: rpage@labpath.com

Received 18 August 2003; accepted 16 October 2003; published online 19 December 2003 deafness. In mice, homozygous deletion of Mitf produces complete loss of melanocytes in the skin and other organs, suggesting that Mitf is essential for the development of melanocytes. ${ }^{1}$ Recent studies have demonstrated the antibody generated against human Mitf is reactive with metastatic malignant melanoma and appears to be a sensitive marker for melanocytes as well as melanocytic neoplasms. ${ }^{2-6}$

In the diagnostic evaluation of a lesion suspected to be a cellular neurothekeoma, we observed reactivity with Mitf. This led us to review the immunohistochemical profile of all the cellular neurothekeomas in our laboratory with regard to staining with Mitf, S-100 and NKI/C3.

\section{Materials and methods}

All of the cases studied were obtained from the files of Knoxville Dermatopathology Laboratory, Knoxville, TN. Only formalin-fixed paraffin embedded tissue was used. Histologically, cases were classified cytomorphologically according to whether or not they contained predominantly epithelioid cells, predominantly spindled cells, or a mixture of both. This was done in accordance with the original 
Table 1 Antibodies

\begin{tabular}{lll}
\hline Antibody & Source & Dilution \\
\hline $\begin{array}{l}\text { Microphthalmia } \\
\text { transcription }\end{array}$ & Dana Farber & Undiluted \\
factor [D5] & Cancer & $\begin{array}{l}\text { hybridoma } \\
\text { culture }\end{array}$ \\
& $\begin{array}{l}\text { Institute, } \\
\text { Boston, MA, }\end{array}$ & supernatant \\
& USA & \\
S-100 & Dr DE Fisher & $1 / 400$ \\
NKIC3 & DAKO & Prediluted \\
\hline
\end{tabular}

description of Rosati et al. ${ }^{7}$ Patient clinical information regarding the lesions was collected.

\section{Immunohistochemistry}

The primary antibodies used are listed in Table 1. Paraffin blocks were sectioned into $3-\mu \mathrm{m}$-thick sections and mounted on Plus (+) slides. Endogenous peroxidase was blocked by incubation in $3 \%$ hydrogen peroxidase. For S-100, sections were digested with trypsin for $15 \mathrm{~min}$ at $37^{\circ}$. This was followed by a protein block (Biocare) for $10 \mathrm{~min}$ and incubation with S-100 for $1 \mathrm{~h}$ at room temperature. After rinsing with PBS, slides were incubated with a secondary antibody (goat anti-rabbit IgG, BioCare) for $15 \mathrm{~min}$ at room temperature, and subsequently with streptavidin-HRP for $15 \mathrm{~min}$. Slides were developed with aminoethylcarbizole chromogen (BioCare).

Immunohistochemistry for Mitf and NKI/C3 was carried out in a similar fashion but with a heatinduced antigen retrieval in Reveal (BioCare) solution for $35 \mathrm{~min}$. In evaluating positive staining, only nuclear staining for Mitf was regarded as valid.

\section{Results}

All 11 cases were characterized by a dermal proliferation of neoplastic cells filling and expanding the superficial and deep dermis. The lesions extended up to, but did not involve the overlying epidermis. A junctional melanocytic proliferation was not identified in any of the cases. The lesions were characterized by nests and fascicles of cells with no appreciable mucinous stroma. The nested growth pattern bore resemblance superficially to dermal nevi, however, the lack of maturation, growth into the deep dermis and poor circumscription, were consistent with cellular neurothekeoma. In addition, all cases were S-100 negative. Cytologically, six cases showed a mixed spindled and epithelioid pattern, three were mostly spindled and two were mostly epithelioid. The clinical information is summarized in Table 2.

The immunohistochemical and histological analysis of the cellular neurothekeomas is summarized in Figure 1 and in Tables 3 and 4 . Nine of 11 tumors
Table 2 Clinical information

\begin{tabular}{rcl}
\hline Case & Age/sex & Location \\
\hline 1 & $22 / \mathrm{F}$ & Left shoulder \\
2 & $14 / \mathrm{M}$ & Right neck \\
3 & $8 / \mathrm{M}$ & Nasal ala \\
4 & $45 / \mathrm{F}$ & Thigh \\
5 & $48 / \mathrm{F}$ & Left nose \\
6 & $7 / \mathrm{M}$ & Below left nostril \\
7 & $17 / \mathrm{F}$ & Right lower limb \\
8 & $17 / \mathrm{F}$ & Posterior neck \\
9 & $19 / \mathrm{F}$ & Left nostril crease \\
10 & $48 / \mathrm{F}$ & Left wrist \\
11 & $51 / \mathrm{F}$ & Nose \\
\hline
\end{tabular}

each stained with both NKI/C3 and Mitf. None stained with S-100. The two tumors, which failed to stain with NKI/C3, were mostly spindled. One of the two tumors, which was negative with Mitf, was almost exclusively spindled and the other showed an evenly mixed, spindled and epithelioid morphology. The two mostly epithelioid tumors showed strong reactivity for Mitf.

\section{Discussion}

In 1980, Gallaher and Helwig ${ }^{5}$ published a report on a series of benign tumors of nerve sheath origin that were dissimilar from any previously described. They $^{5}$ coined the term 'neurothekeoma' with reference to the Greek word oeke meaning sheath. Since then, these tumors have been further subdivided into myxoid or classical type and cellular variants. The cellular type of neurothekeoma was presented in two separate descriptions, the first from Italy by doctors Rosati, Fratamico and Eusebi in 1986, and a subsequent description from Barnhill and Mihm in 1990. Both papers described cellular neurothekeoma as consisting of neoplastic cells forming nests localized in the dermis or focally in the subcutaneous tissue. The nests were discrete and contained round to oval epithelioid cells with abundant eosinophilic or amphophilic cytoplasm with overlapping of usually well-defined cell membranes. The nuclei were vesicular and had dispersed chromatin patterns; however, pleomorphism and hyperchromatism were seen in some lesions., ${ }^{7,8}$ Clinically, these tumors occur predominantly on the head and neck areas of young women.

Immunohistochemical analysis has failed to completely characterize the histogenesis or differentiation of cellular neurothekeoma. Despite the purported hypothesis of this tumor being of neural origin, it fails to stain with S-100 like its classical counterpart. ${ }^{5,9-11}$ It has, however, been noted to stain with some neural markers, including PGP 9.5, and, more interestingly, melanocyte markers, including NKI/C3. ${ }^{11,12}$ Other studies have shown it to be smooth muscle actin positive (see Table 5). 
232


Figure 1 Staining of Mitf and NKI/C3 in cellular neurothekeoma: (a) hematoxylin and eosin, $\times 100$; (b) Mitf, $\times 100$; (c) NKIC3, $\times 100$.

The goal of this study was to characterize the combination of Mitf and NKI/C3 expression in cellular neurothekeomas. As is evidenced in the
Table 3 Morphologic and immunohistochemical results

\begin{tabular}{ccccc}
\hline Case & Type & Mitf & NKI/C3 & S100 \\
\hline 1 & S+E & + & + & - \\
2 & S+E & - & + & - \\
3 & S+E & + & + & - \\
4 & S & Focal+ & - & - \\
5 & S & + & + & - \\
6 & E & + & Weakly + & - \\
7 & S & - & - & - \\
8 & S+E & + & + & - \\
9 & E & + & + & - \\
10 & S+E & + & + & - \\
11 & S+E & + & + & - \\
\hline
\end{tabular}

Table 4 Summary of results by morphology

\begin{tabular}{lcccc}
\hline & Epithelioid & Spindled & Mixed & Total \\
\hline Mitf & $2 / 2$ & $2 / 3$ & $5 / 6$ & $9 / 11$ \\
NKI/C3 & $2 / 2$ & $1 / 3$ & $6 / 6$ & $9 / 11$ \\
\hline
\end{tabular}

Results, a majority of the tumors we studied, regardless of histologic/cytologic subtype, stained strongly with Mitf and NKI/C3 markers. NKI/C3 expression has been well documented in previous studies and has consistently shown strong staining. ${ }^{11}$ This marker, however, does not exclusively stain melanocytic markers, and also stains a variety of tumors and cell types showing neuroectodermal characteristics. To our knowledge, Mitf has been heretofore undescribed and uncharacterized in cellular neurothekeoma.

Mitf expression is not exclusive to melanocytic tumors. Mitf expression has been observed in other tumors including angiomyolipoma and other neoplasms belonging to the class of PEComas or perivascular epitheloid cell tumors. ${ }^{13,14}$ Its expression has also been well characterized in mast cells. ${ }^{15}$ We have found Mitf to be a reliable and helpful marker in our immunohistochemical studies of possible melanocytic neoplasia. However, one study has openly questioned the value of Mitf as a melanocyte-specific antigen. ${ }^{16}$

The Mitf reactivity in cellular neurothekeoma observed in our small study raises several points of interest, but fails to define the histogenesis of cellular neurothekeoma. It is possible that Mitf expression is an additional evidence that cellular neurothekeoma is a tumor of neuroectodermal origin as suggested by others, including those demonstrating it to have other neuroectodermal markers such as PGP 9.5. ${ }^{11}$ Also possible, and most intriguing, is the concept that a cellular neurothekeoma could be in the family of the PEComas that express both smooth muscle markers and melanocyte markers. $^{17,18}$ Previous immunohistochemical studies and ultrastructural structures have demonstrated that cells in cellular neurothekeoma show features 
Table 5 Summary of previous studies

\begin{tabular}{|c|c|c|c|}
\hline Study, year (ref) & $\begin{array}{l}\text { Number } \\
\text { of cases }\end{array}$ & Positive staining & Negative staining \\
\hline Fullen et al, $2003^{10}$ & 7 & S-100A6, PGP 9.5 & S-100 \\
\hline Laskin et al, $2000^{24}$ & 11 & Colllagen type IV, SMA, calponin & $\begin{array}{l}\text { S-100, GFAP, CD57, CD34, EMA, NF, p75ngfr, } \\
\text { Factor XIIIa }\end{array}$ \\
\hline Chang et al, $1999^{25}$ & 1 & $\begin{array}{l}\text { NKI/C3,SMA, NSE, synaptophysin, } \\
\text { chromogranin }\end{array}$ & $\begin{array}{l}\text { S-100, CD34, Factor XIIIa, CD } 68, \text { HMB-45, CK } \\
\text { EMA }\end{array}$ \\
\hline Zelger et al, $1998^{21}$ & 15 & $\begin{array}{l}\text { NKI/C3, KiM1p, PCNA, NSE, Factor } \\
\text { XIIIa, SMA, vimentin }\end{array}$ & $\begin{array}{l}\text { S-100, CD68, MBp, GFAP, NSE, NF, CD34, } \\
\text { CD31, Factor VIII, ulex, desmin, myoglobin, } \\
\text { KL1, EMA, E9 }\end{array}$ \\
\hline Tomasini et al, $1996^{26}$ & 2 & Vimentin, SMA, & $\begin{array}{l}\text { S-100, HMB-45, NSE, EMA, CK, desmin, } \\
\text { CD68 }\end{array}$ \\
\hline Argenyi et al, $1995^{19}$ & 11 & Collagen type IV, SMA, NSE, vimentin & $\begin{array}{l}\text { S-100, CD57, GFAP, MBp, NSE, DP keratin, } \\
\text { HMB-45, CD34, Factor XIIIa }\end{array}$ \\
\hline Husain et al, $1994^{23}$ & $14+$ & MBP, EMA & A-1-ACT, MAC-387, KP-1, SMA \\
\hline Argenyi et al, $1993^{20}$ & 4 & NSE,SMA, CD57 & $\begin{array}{l}\text { S-100, Collagen IV, GFAP, NF, EMA, MBp, DP } \\
\text { keratin, HMB- } 45 \text {, chromogranin, A1-ACT, } \\
\text { desmin }\end{array}$ \\
\hline Calonje et al, $1992^{12}$ & 9 & NKI/C3, NSE, SMA & S-100, desmin, EMA, PGP 9.5, HMB-45 \\
\hline Barnhill et al, $1991^{9}$ & 8 & Vimentin & S-100, MBP, EMA, GFAP \\
\hline Barnhill and Mihm $1990^{16}$ & 5 & & $\begin{array}{l}\text { S-100, MBP, EMA, keratin, A1-ACT, } \\
\text { lysozyme, A1-AT, }\end{array}$ \\
\hline Rosati et al, $1986^{7}$ & 3 & & $\begin{array}{l}\text { S-100, lysozyme, A1-AT, MBP, Factor VIII, } \\
\text { keratin, desmin }\end{array}$ \\
\hline
\end{tabular}

$\mathrm{SMA}=$ smooth muscle actin; GFAP = glial fibrillary acidic protein; $\mathrm{EMA}=$ epithelial membrane antigen; $\mathrm{NF}=$ neurofilament; A1-ACT $=$ alpha 1 anti-chymotrypsin; A1-AT =alpha-1-antitrypsin; $\quad \mathrm{CK}=$ cytokeratin; $\mathrm{MBP}=$ myelin basic protein; NSE = neuron specific enolase; $\mathrm{E} 9=$ antimetallothionein.

Note: Equivocal or variable staining results not included.

of Schwann cells, fibroblasts, myofibroblasts, and smooth muscle cells. ${ }^{19,20}$ In our experience, these lesions stain in about 50 percent of cases with SMA (MC Mihm Jr, personal observation). Other studies have also shown that cellular neurothekeoma does not actually represent a variant of neurothekeoma and is in fact a tumor of another cell type. ${ }^{21}$ Calonje et $a{ }^{12}{ }^{12}$ suggested with their immunohistochemical and light microscopic study that cellular neurothekeoma was in fact an epithelioid variant of a pilar leiomyoma. In addition, Mitf positivity has been shown in PEComas. ${ }^{17,18}$

The variable immunohistochemical and ultrastructural profile of cellular neurothekeoma may be evidence of a neoplasm that undergoes variable phenotypic differentiation. This feature has been expressed in vitro in angiomyolipomas, which also demonstrate reactivity with Mitf. An angiomyolipoma cell line demonstrated variable terminal differentiation into smooth muscle, fat, and melanocytic cells. ${ }^{22}$ Ultrastructural studies in cellular neurothekeoma have shown similar phenotypic variation. ${ }^{19,20}$

Another point of interest is that the Mitf reactivity of cellular neurothekeomas could potentially cause diagnostic confusion with melanocytic neoplasms. Spitz nevus and malignant melanoma, primary and metastatic, can show features very similar to cellular neurothekeoma. Careful histologic study and a panel of immunohistochemical markers are required for accurate diagnosis. Cellular neurothekeomas do not contain melanin pigment and do not have a junctional or intraepidermal presence. Cellular neurothekeomas are negative for S-100 and HMB$45 .^{23,24}$

In conclusion, cellular neurothekeoma can show positivity for both NKI/C3, and Mitf, two 'melanocytic markers.' This observation should help prevent diagnostic error in classification of cellular neurothekeoma and may be evidence that cellular neurothekeoma is a type of myomelanocytic tumor in the family of perivascular epithelioid cell tumors.

\section{Acknowledgements}

We thank Susan Bryant for her invaluable assistance in immunohistochemical staining.

\section{References}

1 Tachibana M. Evidence to suggest that expression of MITF induces melanocyte differentiation and haploinsufficiency of MITF causes Waardenburg syndrome type 2A. Pigment Cell Res 1997;10:25-33.

2 King R, Weilbaecher KN, McGill G, et al. Microphthalmia transcription factor. A sensitive and specific melanocyte marker for melanoma diagnosis. Am J Pathol 1999;155:731-738.

3 O'Reilly FM, Brat DJ, McAlpine BE, et al. Microphthalmia transcription factor immunohistochemistry: a useful diagnostic marker in the diagnosis and detection of cutaneous melanoma, sentinel lymph nodemetastases, and extracutaneous melanocytic neoplasms. J Am Acad Dermatol 2001;45:414-419. 
4 King R, Googe PB, Weilbaecher KN, et al. Microphthalmia transcription factor expression in cutaneous benign, malignant melanocytic, and nonmelanocytic tumors. Am J Surg Pathol 2001;25:51-57.

5 Gallager RL, Helwig EB. Neurothekeoma-a benign cutaneous tumor of neural origin. Am J Clin Pathol 1980;74:759-764.

6 Miettinen M, Fernandez M, Franssila K, et al. Microphthalmia transcription factor in the immunohistochemical diagnosis of metastatic melanoma: comparison with four other melanoma markers. Am J Surg Pathol 2001;25:205-211.

7 Rosati LA, Fratamico FC, Eusebi V. Cellular neurothekeoma. Appl Pathol 1986;4:186-191.

8 Barnhill RL, Mihm Jr MC. Cellular neurothekeoma. A distinctive variant of neurothekeoma mimicking nevomelanocytic tumors. Am J Surg Pathol 1990;14: 113-120.

9 Barnhill RL, Dickersin GR, Nickeleit V, et al. Studies on the cellular origin of neurothekeoma: clinical, light microscopic, immunohistochemical, and ultrastructural observations. J Am Acad Dermatol 1991;25:80-88.

10 Fullen DR, Lowe L, Su LD. Antibody to S100a6 protein is a sensitive immunohistochemical marker for neurothekeoma. J Cutan Pathol 2003;30:118-122.

11 Wang AR, May D, Bourne P, et al. PGP9.5: a marker for cellular neurothekeoma. Am J Surg Pathol 1999;23: 1401-1407.

12 Calonje E, Wilson-Jones E, Smith NP, et al. Cellular 'neurothekeoma': an epithelioid variant of pilar leiomyoma? Morphological and immunohistochemical analysis of a series. Histopathology 1992; 20:397-404.

13 Makhlouf HR, Ishak KG, Shekar R, et al. Melanoma markers in angiomyolipoma of the liver and kidney: a comparative study. Arch Pathol Lab Med 2002;126: 49-55.

14 Stone CH, Lee MW, Amin MB, et al. Renal angiomyolipoma: further immunophenotypic characterization of an expanding morphologic spectrum. Arch Pathol Lab Med 2001;125:751-758.

15 King R, Peterson AC, Peterson KC, et al. Microphthalmia transcription factor expression in cutaneous mast cell disease. Am J Dermatopathol 2002;24:282-284.
16 Busam KJ, Iversen K, Coplan KC, et al. Analysis of microphthalmia transcription factor expression in normal tissues and tumors, and comparison of its expression with S-100 protein, gp100, and tyrosinase in desmoplastic malignant melanoma. Am J Surg Pathol 2001;25:197-204.

17 Folpe AL, Goodman ZD, Ishak KG, et al. Clear cell myomelanocytic tumor of the falciform ligament/ ligamentum teres: a novel member of the perivascular epithelioid clear cell family of tumors with a predilection for children and young adults. Am J Surg Pathol 2000;24:1239-1246.

18 Folpe AL, McKenney JK, Li Z, et al. Clear cell myomelanocytic tumor of the thigh: report of a unique case. Am J Surg Pathol 2002;26:809-812.

19 Argenyi ZB, Kutzner H, Seaba MM. Ultrastructural spectrum of cutaneous nerve sheath myxoma/cellular neurothekeoma. J Cutan Pathol 1995;22:137-145.

20 Argenyi ZB, LeBoit PE, Santa Cruz D, et al. Nerve sheath myxoma (neurothekeoma) of the skin: light microscopic and immunohistochemical reappraisal of the cellular variant. J Cutan Pathol 1993;20:294-303.

21 Zelger BG, Steiner $\mathrm{H}$, Kutzner $\mathrm{H}$, et al. Cellular 'neurothekeoma': an epithelioid variant of dermatofibroma? Histopathology 1998;32:414-422.

22 Arbiser JL, Yeung R, Weiss SW. The generation and characterization of a cell line derived from a sporadic renal angiomyolipoma: use of telomerase to obtain stable populations of cells from benign neoplasms. Am J Pathol 2001;159:483-491.

23 Husain S, Silvers DN, Halperin AJ, et al. Histologic spectrum of neurothekeoma and the value of immunoperoxidase staining for S-100 protein in distinguishing it from melanoma. Am J Dermatopathol 1994;16: 496-503.

24 Laskin WB, Fetsch JF, Miettinen M. The 'neurothekeoma': immunohistochemical analysis distinguishes the true nerve sheath myxoma from its mimics. Hum Pathol 2000;31:1230-1241.

25 Chang SE, Lee TJ, Ro JY, et al. Cellular neurothekeoma with possible neuroendocrine differentiation. J Dermatol 1999;26:363-367.

26 Tomasini C, Aloi F, Pippione M. Cellular neurothekeoma. Dermatology 1996;192:160-163. 